\title{
Has Indonesia's Diplomacy Really Gone Digital?
}

\author{
Muhammad Tri Andika ${ }^{1}$, Bani Pamungkas ${ }^{2}$, Muhammad Badaruddin ${ }^{3}$, Suharyanti $^{4}$ \\ \{andika.kurniawan@bakrie.ac.id ${ }^{1}$ \} \\ Universitas Bakrie, Indonesia ${ }^{1,2,3,4}$
}

\begin{abstract}
The rise of the internet and information communication technology (ICT) has signified the role of digital diplomacy for the current foreign policy. Since recent times, countries across the world inevitably have to deal with the increasing use of the internet. Under Joko Widodo's administration, Indonesia's Ministry of Foreign Affairs (MOFA) responds to this trend by embracing digital technology on their work. Its commitment can be traced from the document of the National Medium-Term Development Plan 2015-2019 and the document of Strategic Planning of Indonesia's MOFA 2014-2019. In practice, Indonesia's MOFA vigorously grasped to implement digital diplomacy by asserting the importance of website, social media, and mobile application to support their work. However, in this regard, is Indonesia diplomacy really going digital? This article argues that Indonesia's digital diplomacy, even in recent times, continues to lack substance and a framework. Digital diplomacy involves more than mere transformation of the content or conversation into digital media. Therefore, it is necessary that digital diplomacy is equipped with strategic planning and solid framework which are manifested in the blueprint or road map document. Yet, the practice of Indonesia's digital diplomacy is not armed with these documents. Therefore, this paper argues that the effort of Indonesia's MOFA to build a strategic road map document is essential in managing various problems and challenges in implementing digital diplomacy.
\end{abstract}

Keywords: Digital, Diplomacy, Foreign Policy, Indonesia.

\section{Introduction}

Under Joko Widodo's administration, there is growing attention towards adopting digital technology in its diplomatic activities. In the last 4 years, we witnessed that Indonesia's Minister of Foreign Affairs has aggressively embraced digital diplomacy, using online platforms such as websites and social media to send their messages to public, providing more channels to engage with the government's foreign policy. However, digital diplomacy involves more than just posting diplomatic agenda or a state's foreign policy into the website or social media. These activities are just the tip of the iceberg.

The rise of internet and information communication technology (ICT) has signified the role of digital diplomacy for today's foreign policy. They have been considered as one of the prominent trends of the 21 st century in diplomatic communication. Digital diplomacy enables a conversation to surpass the boundaries. It is a new ecosystem, produced by globalisation and marked completely by new actors and entities.

Under Joko Widodo's administration, the Indonesian Ministry of Foreign Affairs (MOFA) responds to that trend by embracing digital technology on their work. Although the basic idea of using online platforms for diplomacy can be traced back to the early 2000s, under Jokowi's 
administration, the MOFA is yet to succeed to encapsulate its importance through the National Medium-Term Development Plan 2015-2019 and the document of Strategic Planning of the Indonesia's MOFA 2014-2019. Specific regulations also have been formulated into the minister decree, strategic objectives, and general main indicators. It shows a strong commitment of Indonesia's MOFA to grasp digital diplomacy on their diplomatic activities.

At the practical level, the Indonesian MOFA vigorously grasped to implement digital diplomacy by asserting the importance of websites, social media, and mobile applications to support their work. Indonesia's MOFA also has encouraged its diplomats to finely tune themselves with the rapid development of digitalisation tools through various training programs. Nevertheless, considering this as a background, is Indonesian diplomacy really going digital?

This paper seeks to understand the growth of Indonesia's digital diplomacy in the era of the internet. This article argues that Indonesia's digital diplomacy, even in recent times continues to lack a framework and focus on the "front-end". Digital diplomacy is more than just transforming content or conversation into digital media. Advanced digital diplomacy should be equipped with strategic planning and a solid framework, which manifests in the blueprint or road map document. Indonesian digital diplomacy should thus be a strategic element of statecraft through a demonstration of its strategic value in advancing foreign policy goals, instead of being a mere tactic in communicating MOFA's positions and interests. In other words, the Indonesian MOFA should not only consider the aspects of digital diplomacy that are easily visible, but also those aspects that are not easily visible. However, the practice of Indonesia's digital diplomacy is still not armed with these. It is from here the question rises: How can one move to the next level of professionalisation of digital diplomacy? This paper argues that the effort of Indonesia's MOFA to build a strategic road map document is essential in managing various problems and challenges in implementing digital diplomacy.

\section{Understanding Digital Diplomacy}

The classical view on digital diplomacy is often strongly associated with public diplomacy. This idea has been studied since 1984, marked by the work of Allen C. Hansen titled "Public Diplomacy in the Computer Age", which explores the public diplomacy exerted by the United States Information Agency (UEIA) [1]. This view has been strengthened by Chakraboty, who defined digital diplomacy as a form of new public diplomacy, which uses the internet, new information and communication technologies (ICT) and social media as means for strengthening diplomatic relations [2]. The differences with the classical public diplomacy are located in the aspects of greater access to information, interaction among individuals and organisations, and transparency.

Diplomacy itself, according to Cohen, is the "engine room" of international relations [3].The internet technology is an instrument "online power", aimed to promote the state's national interest in international relations [4]. The Internet, as argued by Friedman, has played an important role enabling any stakeholders living anywhere to access the same information, to connect to and conduct business directly with each other. The adoption of these ways was triggered by several factors. First, the internet technology has amplified the number of voices and interests involved in international policymaking, complicating international decisionmaking and reducing the exclusive control of states in the process. Second, it accelerates the 
dissemination of information. Third, the internet has enabled traditional diplomatic services to be delivered faster and more cost effectively [5].

The nexus between the development of internet and diplomacy has invited various debates. Through its development, the relationship between two concepts has been commonly known as digital diplomacy. There are some contesting definitions to understand digital diplomacy. However, strikingly, there is no widely accepted definition or framework that covers the concept.

According to Manor and Segev [6], digital diplomacy is related to the growing use of social media platforms by states in order to achieve its foreign policy goals and proactively manage its image and reputation. Lewis defines digital diplomacy as the use of digital tools of communication or social media by diplomats to communicate with each other and with the general public [7]. In another words, Potter defines digital diplomacy as diplomatic practices through digital and networked technologies, including the Internet, mobile devices, and social media channels [8]. Holmes emphasized that digital diplomacy was a "strategy of managing change through digital tools and virtual collaborations", adding an emphasis to the inherent collaborative nature of diplomacy both online and offline, which the digital does not affect in any way [9]. From these definitions, we may see that there is no widely accepted framework but the mere placement of any diplomatic message into online platforms.

Some researchers tried to look at digital diplomacy from a different perspective, more than adopting ICT's advancement into diplomatic activities. Digital diplomacy, as viewed by Mellisen, is a form of the diplomatic practice It is an instrument used by a state's diplomat to understand cultures, attitudes, and behaviour; build and manage relationships; and influence thoughts and mobilise actions to advance their interests and values [3]. Under this context, digital diplomacy has also increased the number of stakeholders participating in international diplomacy, and not merely from state-to-state interactions, but also from international organizations and international non-governmental organizations. [10].

According to Manor and Segev, digital diplomacy refers mainly to the growing use of social media platforms by the state's diplomat in order to achieve its foreign policy objectives and to manage its image and reputation [11]. Lewis defines digital diplomacy as the use of digital tools of communication (social media) by diplomats to communicate with each other and with the general public [12]. According to Potter, digital diplomacy refers to the diplomatic practices through digital and technology, including the Internet, mobile devices, and social media channels [8]. It is also worth noting that digital diplomacy has been used interchangeably with other terms - as digital diplomacy, e-diplomacy, cyber-diplomacy, diplomacy 2.0 or twiplomacy [13].

Digital diplomacy also could be seen through the perspective of soft power. Soft power, according to Joseph Nye, is the ability to set the agenda in world politics through persuasion, enticing and attracting others through by forcing a person's beliefs, values and ideas, and not through military or economic coercion. As stressed by Nye, the two types of power can be differentiated into hard and soft power. Hard power is "the ability to get others to act in ways that are contrary to their initial preferences and strategies". This is the ability to coerce, through threats and inducements. On the contrary, soft power is the ability to get "others to want the outcomes that you want", and more particularly "the ability to achieve goals through attraction instead of coercion" [14]. This view, strengthened by Hallams who believed that "the art of soft power in the twenty-first century is fusing the traditional tools of diplomacy and negotiation and the ability to harness the power and potential inherent in the new and emerging technologies that globalization has wrought" [15]. 
Although the idea of digital diplomacy is dominantly about the use of ICT to articulate the state's foreign policy. However, that perspective is not enough, particularly in conducting substantive digital diplomacy. This article examined digital diplomacy through the perspective of Corneliu Bjola, which highlighted a growing understanding that digital diplomacy must move beyond the current focus on the public-facing, "front-end" of digital diplomacy (message dissemination and engagement) and focus carefully on designing the "back-end" models supporting their digital strategies and operations (data analysis and network development). It is the way for the Minister of Foreign Affairs to be able to proceed to the next level of professionalization of digital diplomacy [16].

Furthermore, to measure the development of Indonesia's digital diplomacy, we might use two general variables proposed by Graffy and Schlechter: the level of complexity and the level of interaction. The level of complexity is explained as to the foreign ministries and the diplomats who can implement the use of sophisticated and advanced technological tools in their diplomatic duties [19]. However, it is not only as simple as something which has a complex interface installed at all the embassies' office, but also can fosters deep engagement with the world at large. Another variable is the level of interaction. It can be understood as the extent to which the ministry of foreign affairs is able to use technology to reach out to people concerned with its activities [17]. It is the use of IT systems to interact with and affect host countries, citizens, the public, and other international organizations who may either have a direct or indirect stake in the activities of the ministry.

\section{Indonesia's Digital Diplomacy}

In the past five years, Indonesia is among the countries that aggressively adopted digital technology in their diplomacy activities. Reported by the Indonesian MOFA as released by the Digital Diplomacy Review 2017, the Indonesian digital diplomacy ranked $8^{\text {th }}$ in Asia [18]. While Indonesia ranks below Asian countries like Japan and India, it excels among the Southeast Asian countries. In addition, according to the Diplomacy ranking, the twitter account of the MOFA took the fourth position as the most reliable government account. In the domestic context, the twitter account of the Indonesian Ministry of Foreign Affairs ranks $4^{\text {th, }}$ just under account of the President, the Presidential Office Staff, and the Cabinet Secretariat. According to the Indonesian MOFA, it shows that digital media accounts have a high level of public trust as a source of information about Indonesian diplomacy.

Under Jokowi's administration, the institutionalization of digital diplomacy has been formalized under several regulations. Jokowi's umbrella foreign policy, called "pro-people diplomacy", emphasizes the state's presence for Indonesia's society. Through the adoption of online platforms to disseminate information and the key message of a state's foreign policy, it may increase the state's presence in Indonesian people. This commitment was then confirmed through MOFA's decree No.2/2016 about organization, by which the digital diplomacy became one of the areas of their focus.

As implementation of digitalization in their diplomacy activities, Indonesia's MOFA has been actively engaged not only thorough the website, but also through social media platforms. The first launching of Indonesia's MOFA website was in 1996. This was also the first channel for Indonesia's MOFA to disseminate their information and other foreign policy agenda 
through internet technology. This website then has passed several developments in 2008, 2016, and 2019.

Indonesian MOFA also has managed several social media accounts, such as a Facebook Page, Twitter, and an Instagram page. Moreover, MOFA has launched the audio-visual platform for disseminating information in the form of Foreign Ministry TV (Kemlu TV). This channel is embedded through MOFA's website. In addition, in January 2017, the Indonesian Foreign Minister also announced new initiatives, namely a beta version of a mobile application called Safe Travel [19]. This mobile app's function benefits Indonesian citizens who are travelling abroad. In addition to Safe Travel apps, MOFA also has used "smart embassy" and "SMS blast" to improve the protection services for Indonesian citizens abroad. The government also has a Rogatory Online Monitoring (ROM) website and Rogatori Management Information System (Rogatori SIM) to improve the quality of handling legal technical assistance in civil matters, in an effort improve the services for justice seekers, both in Indonesia and abroad.

Diagram 1. Instruments of Indonesian Digital Diplomacy

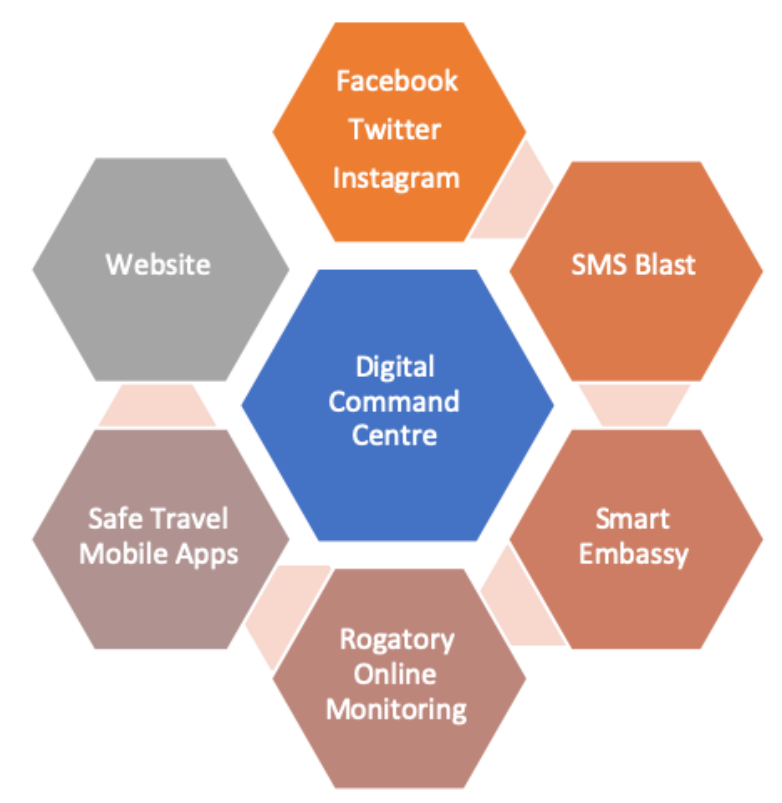

According to the 2018 annual report of Indonesian MOFA, the percentage achievement of digital diplomacy agenda is about $60.17 \%$, decreased from 2017 which was about $75.86 \%$. This percentage is obtained from several indicators, namely positive sentiments of the news on Indonesia's foreign policy, public impression and engagement with MOFA's social media, the number of visitors to MOFA's website, and MOFA's open information ranking. The positive sentiments of domestic news on Indonesian Foreign Policy in 2018 was about $96.31 \%$, while in 2017 , it was about $96,83 \%$. In 2017 there was $33.997 \%$ of positive sentiments on domestic news and $35.109 \%$ on international news. Strikingly, the number of public engagements has increased significantly. The increasing number of engagements on MOFA's social media reached 29.234 .883 times or $384 \%$ in 2018 , while in 2017 , it was about 18.547 .401 or $243.62 \%$. It has increased by $140.39 \%$. The number of website's visitor also increased. In 
2017, the total visitors of MOFA's website was about 1.731 .762 , and in 2018, it reached 2.533.310 visitors. It has increased by $46,29 \%$ from 2017 to 2018. However, for the open information, ranking is to be used only as indicators in 2018, where the MOFA was ranked $9^{\text {th }}$.

Table 1. Main indicators of Indonesia Digital Diplomacy

\begin{tabular}{|c|l|c|c|}
\hline No & \multicolumn{1}{|c|}{ Indicators } & $\mathbf{2 0 1 7}$ & $\mathbf{2 0 1 8}$ \\
\hline 1 & Positive sentiment in domestic news & $96,31 \%$ & $96,36 \%$ \\
\hline 2 & Positive sentiment in International news & $88,39 \%$ & $83,12 \%$ \\
\hline 3 & $\begin{array}{l}\text { Public impression and engagement on social } \\
\text { media }\end{array}$ & - & $140,39 \%$ \\
\hline 4 & Website visitors & - & $46,29 \%$ \\
\hline 5 & Open public Information Ranking & - & 9 \\
\hline
\end{tabular}

In the MOFA's organization, digital diplomacy is managed under the Directorate General of Information and Public Diplomacy. This directorate is responsible for manage information, public diplomacy, diplomatic security, and technical cooperation, which also includes the management of digital diplomacy. However, by placing digital diplomacy in the directorate general of information and public diplomacy, it indicates that digital diplomacy in Indonesia still focuses on public diplomacy, as argued by the classical perspective which emphasized digital diplomacy as a part of public diplomacy.

An important step has also been taken institutionally to strengthen digital diplomacy. To enhance digital diplomacy, Indonesia's MOFA established the DCC (Digital Command Centre) in 2017. However, this body is still placed under the Directorate General of Indonesia and Public Diplomacy functioning to monitor and analyze the trend of public response over Indonesia's foreign policy. In addition to managing social media and website management, the task of the Digital Command Centre is to collect data from open sources. DCC is also the coordination center of the Indonesian Ministry of Foreign Affairs and Indonesian Representatives abroad.

What the Indonesia MOFA has done has fulfilled two variables, namely complexity and interaction. The level of complexity of Indonesian digital diplomacy is compiled at least through six instruments of digital platforms, namely social media, websites, SMS-blast, smart embassy, Rogatory Online Monitoring, and Safe Travel mobile apps [18]. It is the current technology are run by the Indonesian MOFA, which has claimed to have succeeded in triggering interaction as well as public positive sentiments and engagement significantly. It has been reflected through five main indicators developed by MOFA as a measurement of the impact and successful of their digital diplomacy program. However, an important question which remains it is whether it really reflected substantive digital diplomacy.

\section{Central challenge}

This article stressed that while Indonesia's MOFA has showed a strong commitment towards embracing digital diplomacy through optimizing the use of internet technology in disseminating information, it is still not enough to really being digital in their diplomacy. The central reason of this article put on it is that Indonesia has not produced a clear policy or blueprint on digital diplomacy. Hence, despite strong commitments on managing digital diplomacy through websites and others social media platforms, Indonesia's MOFA digital 
diplomacy has not arrived yet, using Nye's concept as a soft power for Indonesia's foreign policy. It indicates that Indonesia's digital diplomacy is still a tool, instrument, and a tactic. It is not a strategy yet.

Indonesian Foreign Minister Retno Marsudi revealed that digital diplomacy has become an important era in Indonesia's foreign policy [20]. To implement this view, there are some efforts that have taken by the Indonesian MOFA, such as placing digital diplomacy into MOFA's strategic plan, and issuing some decrees to enhance the framework of digital diplomacy. It has passed several steps. In 2017, the Ministry of Foreign Affairs of Indonesia issued the Decree No. 84/2017 concerning changes to the 2017 Ministry of Foreign Affairs Main Strategy and Working Indicator Map. This decree is a significant effort to increase the policy level of digital diplomacy to be more strategic. According to this decree, the process of achieving strategic targets must be supported by maritime diplomacy, social and cultural economic diplomacy, service and protection of Indonesian citizens, digital diplomacy, and national support and commitment on foreign policy. It marks a new milestone for digital diplomacy in the policy level.

Previously, the general framework of digital diplomacy was only written in the level of Foreign Minister Regulation No. 2 of 2016 concerning the Organization and Work Procedure of the Ministry of Foreign Affairs of the Republic of Indonesia. In the regulation, it was explained that digital diplomacy has become one of the focuses of the Ministry of Foreign Affairs, particularly the Bureau of Strategic Support of the Leadership, and Media Relations. To strengthen the framework, in addition to MOFA's Decree No.84/2017, in 2018 MOFA also has issued a Decree of the Ministry of Foreign Affairs No.10/2018 on Digital Media Management. In the policy perspectives, these documents are the reference to implement digital diplomacy to support Indonesia's foreign policy.

However, while these documents have been very technical on how to post and articulate a message into digital media, it still lacks grand value, which may be demonstrated to international audience. This paper suggests that Indonesia's digital diplomacy should more than just transforming content or conversation into digital media. Advanced digital diplomacy must be equipped with strategic planning and solid framework, which are manifested in the blueprint or road map document. The strategic document must consist of a strategy to increase Indonesia's value, for example, as peaceful democratic Muslim countries, investment-friendly countries, or the value of its diversity to international communities.

Another breakthrough that may be adopted by Indonesia's MOFA is through the remodeling of the indicator or measurement of digital diplomacy. In the 2018 annual report, Indonesian MOFA adopted five main indicators to measure its digital diplomacy effectiveness; positive sentiment in domestic news, positive sentiment in international news, public engagement in social media, website visitors, and the ranking of open public information. But again, these indicators still focused on the "front-end" of digital diplomacy, which emphasizing message dissemination and engagement. Therefore, it is worth to add another main indicator which may measure the "back-end" of digital diplomacy. Corneliu Bjola, as discussed above, highlighted a growing understanding that digital diplomacy must move beyond the current focus on the public-facing, "front-end" of digital diplomacy message dissemination and engagement- and focus carefully on how to design the "back-end" models supporting their digital strategies and operations- data analysis and network development.

As diplomacy in fact is just an instrument, and not the source of power of a state's foreign policy, the Indonesian digital diplomacy should be used as a strategic element of statecraft by demonstrating its strategic value in advancing foreign policy goals, instead of being a mere 
tactic in communicating the MOFA positions and interests. In other words, Indonesia's MOFA should consider not only the front-end of digital diplomacy, but also the backend of it.

\section{Conclusion}

Although Indonesia has made various efforts on digital diplomacy, they still lack a solid direction. It has made digital diplomacy of Indonesia's MOFA a mere tactic still, and not a strategy. The MOFA should shift its direction from merely transforming the message and information from conventional media to online platforms, to the more advanced digital diplomacy equipped by a comprehensive strategy of how MOFA should be used to support foreign policy objectives. Indonesian MOFA needs more solid blueprint and indicators in defining the specific agenda of their digital diplomacy.

The implementation of digital diplomacy must run through the measurables goals, parameters, and evaluation. Therefore, the digital diplomacy strategy cannot be limited to the front-end and crafting the information, but rather focus on the backend, strategic skills such as measuring digital impacts, identifying quantitative combinations of factors that may shape the impact of foreign policy in real time. Therefore, the Indonesian digital diplomacy should be used as a strategic instrument of statecraft by demonstrating its strategic value in advancing foreign policy objectives, instead of being a tactic in communicating MOFA positions and interests into online platforms.

\section{References}

[1] A. C. Hansen, USIA, public diplomacy in the computer age. Praeger Publishers, 1989.

[2] K. Chakraborty, "Cultural Diplomacy Dictionary," Berlin Acad. Cult. Dipl., 2013.

[3] A. F. Cooper, J. Heine, R. Thakur, and R. C. Thakur, The Oxford handbook of modern diplomacy. Oxford University Press, 2013.

[4] N. Westcott, "Digital diplomacy: The Impact of the internet on international relations," 2008.

[5] T. L. Friedman, The world is flat: A brief history of the twenty-first century. Macmillan, 2005.

[6] C. Bjola, M. Holmes, I. Manor, and E. Segev, “America's Selfie: How the US Portrays Itself on its Social Media Accounts."

[7] US Department of State, "21st century statecraft The 'Internet moment' in foreign policy"," 2019. [Online]. Available: http//www state gov/stagecraft/overview/index htm.

[8] E. H. Potter, Cyber-diplomacy: Managing foreign policy in the twenty-first century. Ontario: McGill-Queen's Press, 2002.

[9] M. Holmes, "The future of digital diplomacy," Digit. Dipl. Theory Pract., pp. 199-206, 2015.

[10] S. Sotiriu, Digital diplomacy: Theory and practice. New York: Routledge, 2015.

[11] C. Manor, I., \& Segev, Digital diplomacy: Theory and practice. New York: Routledge, 2015.

[12] D. Lewis, "Digital Diplomacy," 2014. [Online]. Available: http://www.gatewayhouse.in/digitaldiplomacy-2/.

[13] C. Bjola, Digital diplomacy: Theory and practice. New York: Routledge, 2015.

[14] J. Nye, Soft power: The means to success in world politics. New York: Public Affairs, 2004.

[15] E. Hallams, "Digital Diplomacy: The internet, the battle for ideas \& US foreign policy," $C E U$ Polit. Sci. J., no. 5, pp. 538-574, 2010.

[16] C. Bjola, "Digital Diplomacy Tactics-Strategy," 2018. .

[17] D. Schlechter, When News Lies. New York: Select Books, 2006.

[18] Kementerian Luar Negeri, Laporan Kinerja Tahun 2018. Jakarta: Kemenlu, 2018.

[19] A. M. Tri, P. Bani, and B. Muhammad, "The effect of dialogic communication in safe travel 
application on digital diplomacy of the Ministry of Foreign Affairs of the Republic of Indonesia.,” Russ. J. Agric. Socio-Economic Sci., vol. 10, no. 82, pp. 281-294, 2018.

[20] Antara, "Diplomasi Digital Kemenlu Perkuat Politik Luar Negeri," 2017. [Online]. Available: $\mathrm{http} / / /$ www.mediaindonesia.com/news/read/114683/diplomasi-digital-kemenlu-perkuat-politikluar- negeri. 